\title{
Unravelling the dependence of a wild bee on floral diversity and composition using a feeding experiment
}

\author{
Zuzanna M. Filipiak $^{\mathrm{a}}$, Bożena Denisow ${ }^{\mathrm{b}}$, Ernest Stawiarz ${ }^{\mathrm{b}}$, Michał Filipiak ${ }^{\mathrm{a}, *}$ \\ ${ }^{a}$ Institute of Environmental Sciences, Faculty of Biology, Jagiellonian University, Kraków, Poland \\ b Laboratory of Plant Biology, Department of Botany and Plant Physiology, University of Life Sciences in Lublin, Lublin, Poland
}

\section{H I G H L I G H T S}

- Nutritional imbalance can decrease wild bee health and fitness.

- Vital nutrients provided by specific plants may alleviate this negative effect.

- Plant diversity is not necessarily correlated with vital nutrient availability.

- Landscape changes may shape bee populations via diet balancing.

- Plant mixes for bees should be composed considering local flora nutritional supply.

\section{A R T I C L E I N F O}

\section{Article history:}

Received 16 July 2021

Received in revised form 17 January 2022

Accepted 18 January 2022

Available online 21 January 2022

Editor: Rafael Mateo Soria

\section{Keywords}

Conservation

Food base

Nutrition

Pollinator decline

Monoculture

Global change
G R A P H I C A L A B S T R A C T

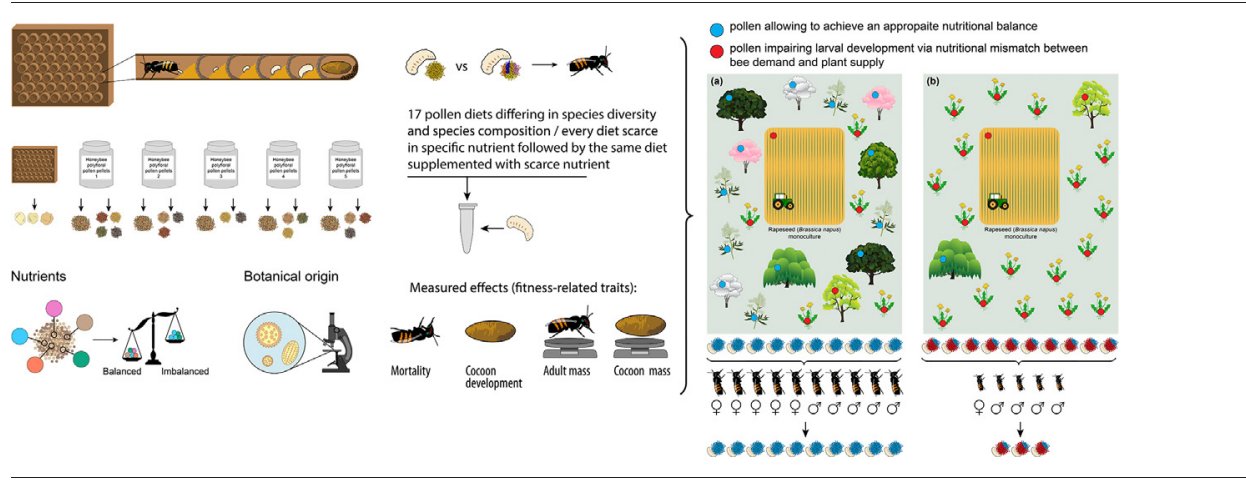

\begin{abstract}
A B S T R A C T
We investigated nutrition as a potential mechanism underlying the link between floral diversity/composition and wild bee performance. The health, resilience, and fitness of bees may be limited by a lack of nutritionally balanced larval food (pollen), influencing the entire population, even if adults are not limited nutritionally by the availability and quality of their food (mainly nectar). We hypothesized that the nutritional quality of bee larval food is indirectly connected to the species diversity of pollen provisions and is directly driven by the pollen species composition. Therefore, the accessibility of specific, nutritionally desirable key plant species for larvae might promote bee populations. Using a fully controlled feeding experiment, we simulated different pollen resources that could be available to bees in various environments, reflecting potential changes in floral species diversity and composition that could be caused by landscape changes. Suboptimal concentrations of certain nutrients in pollen produced by specific plant species resulted in reduced bee fitness. The negative effects were alleviated when scarce nutrients were added to these pollen diets. The scarcity of specific nutrients was associated with certain plant species but not with plant diversity. Thus, one of the mechanisms underlying the decreased fitness of wild bees in homogenous landscapes may be nutritional imbalance, i.e., the scarcity of specific nutrients associated with the presence of certain plant species and not with species diversity in pollen provisions eaten by larvae. Accordingly, we provide a conceptual representation of how the floral species composition and diversity can impact bee populations by affecting fitness-related life history traits. Additionally, we suggest that mixes of 'bee-friendly' plants used to improve the nutritional base for wild bees should be composed considering the local flora to supplement bees with vital nutrients that are scarce in the considered environment.
\end{abstract}

\section{Introduction}

* Corresponding author at: Institute of Environmental Sciences, Michal Filipiak, ul. Gronostajowa 7, 30-387 Krakow, Poland.

E-mail addresses: bozena.denisow@up.lublin.pl (B. Denisow), ernest.stawiarz@up.lublin.pl (E. Stawiarz), michal.filipiak@uj.edu.pl (M. Filipiak).
Although much is understood about the details of the functioning of wild bees, knowledge of connections among the various elements of wild bee nutrition and well-being that would allow a broad, ecosystem- 
oriented understanding of wild bee ecology and conservation is still lacking (Leonhardt et al., 2020; Parreño et al., 2021; Van der Kooi et al., 2021). The functioning and prosperity of wild bee populations are influenced by human activities that cause changes in landscape structures, leading to habitat loss, fragmentation and degradation. As a result, wild bees may be subjected to deficiencies in food resources, which are indicated as one of the most important drivers of their decline (Belsky and Joshi, 2019; Goulson et al., 2015; Parreño et al., 2021; Roulston and Goodell, 2011). The term 'deficiency in food resources' not only means that less food is available but also refers to the decreased nutritional quality of food sources available in inhabited ecosystems. Such changes result in mismatches between what wild bees need and what is offered by their environment, consequently contributing to bee decline (Hemberger et al., 2021; Parreño et al., 2021; Trinkl et al., 2020; Vaudo et al., 2015; Wilson et al., 2021). Within this context, floral diversity has a positive impact on many wild bee populations, providing food sources of diverse botanical origins (Belsky and Joshi, 2019; Di Pasquale et al., 2016; Drossart and Gérard, 2020; Parreño et al., 2021; Wilson et al., 2021). However, the mechanism underlying this positive impact of diverse flora is not fully understood (Parreño et al., 2021). We hypothesize that this mechanism is based on the differences between bee nutritional demands and environmental nutritional supplies: (1) wild bees may be often unable to achieve a nutritional balance in their diets because only a strictly limited number of plant species provide the required resources in the needed proportions (Filipiak, 2019; Parreño et al., 2021; Van der Kooi et al., 2021; Zu et al., 2021), and (2) these plants may be not available in certain landscapes with specific floral compositions, which negatively affects bees (Filipiak, 2019; Hemberger et al., 2021; Jachuła et al., 2017; Parreño et al., 2021; Stein et al., 2020; Wilson et al., 2021; Zajdel et al., 2019).

Ecological stoichiometry, which is defined as the study of the balance of multiple chemical elements in ecological interactions and processes (Sterner and Elser, 2002), allows us to extensively investigate the causes and consequences of nutritional constraints imposed on organisms by unbalanced resources. The growth and development of a fully functioning adult body in any organism depends on the proportions of atoms of approximately 25 vital elements that compose every living cell, tissue, and organ; thus, every organism uses behavioral and physiological adaptations to obtain these elements from food in appropriate proportions and ratios (Kaspari and Powers, 2016; Sterner and Elser, 2002). From the perspective of ecological stoichiometry, the term 'nutrient' denotes atoms of vital elements derived from food and built into the organism, and a 'balanced diet' means that the molar ratio of atoms composing food matches the molar ratio in the consumer's body constructed from this food with consideration of the energy needed (e.g., in the case of invertebrates, $75 \%$ of consumed carbon is released as $\mathrm{CO}_{2}$ to maintain their energetic needs, and the calculation of a 'balanced diet' considers this need (Filipiak, 2019)). This reasoning is based on the most basic rules of life, i.e., (1) the law of the conservation of matter (Sterner and Elser, 2002) and (2) the common biochemistry of all living entities originating in their shared evolutionary history (Elser et al., 2020). Since the production of every organic molecule is limited by the molecule's stoichiometry, the proportion of atoms available in the environment limits biochemical processes underlying the growth, development and functioning of cells, tissues, organs and bodies. The consequence of these key rules of life is a limiting effect imposed on organismal growth, development and functioning if the discrepancy between the stoichiometry of food and the dietary needs of a consumer's body is too high. If such a stoichiometric mismatch is experienced, the consumer must expend considerable physiological effort to absorb nutrients in the required proportions and to avoid a surplus of highly concentrated nutrients. Consequently, the consumer experiences costs, and as a result, stoichiometric mismatches shape ecological interactions among organisms, the life histories of individuals, and ultimately the evolution of species (Sterner and Elser, 2002). Thus, the proportions of atoms composing juvenile food can be used as a proxy for the nutritional quality of this food for the consumer (Filipiak, 2018), as shown in previous studies (e.g., Baggett et al., 2013; Lind and Jeyasingh, 2018; Zhang et al., 2018) and reviews (Kaspari,
2021; Sardans et al., 2021). Clearly, the framework of ecological stoichiometry alone does not cover all aspects of the complicated interactions between bees and plants (Parreño et al., 2021), and it is impossible in a single study to consider all the factors driving bee biology. However, similar studies focusing on bee nutritional ecology within specific research frameworks have been highly informative (e.g., Wood et al., 2021; Ausma et al., 2021 for reviews, see Belsky and Joshi, 2019; Goulson et al., 2015; Parreño et al., 2021; Vaudo et al., 2015; Woodard and Jha, 2017; Wright et al., 2018).

The presented approach was previously verified using theoretical modeling: Filipiak (2019), using the Trophic Stoichiometric Ratio index, computed the stoichiometric mismatch between Osmia bicornis L. and its potential food sources and predicted the elements that colimit the growth and development of this bee species. These predictions were further proven in our preliminary feeding experiment (Filipiak and Filipiak, 2020), in which the scarcity of $\mathrm{Na}, \mathrm{K}$ and $\mathrm{Zn}$ in larval food was limiting for the bees, as predicted by Filipiak (2019). Here, we took this research one step further and designed a feeding experiment in which we associated the nutritional quality of various pollen diets with their species composition. Moreover, we studied the effects of these diets on bee fitness. In this way, we could connect wild bee fitness with the species composition and diversity of floral resources available to bees in various environments. Accordingly, we recreated various nutritional situations in the laboratory, simulating different pollen resources available to bees in various environments, either with or without supplementing the diets with scarce nutrients. We hypothesize that (1) the nutritional quality of wild bee larval food is connected to both the species diversity and species composition of the pollen constituting this food but that (2) the factor directly driving the nutritional quality of the food is the species composition and not the species diversity because (3) the species composition of the pollen provisions, i.e., the presence of specific plant species, is associated with the nutritional quality of the pollen.

We investigated the abovementioned concepts and hypotheses using Osmia bicornis L. (syn. Osmia rufa L., Hymenoptera: Megachilidae; red mason bee), a solitary bee proposed as a model organism for studying wild bee nutritional ecology (Filipiak, 2018) and used previously in studies considering various aspects of bee ecology (e.g., Austin and Gilbert, 2021; Kierat et al., 2017; Szentgyörgyi et al., 2017; see review in (Splitt et al., 2021a)). We are aware of the fact that, although using model organisms to study general questions in ecology is in keeping with current applications of the scientific method, it is impossible to use a theoretically ideal model that covers all aspects of the complicated interactions between organisms and their environment. However, we emphasize that in the present study, we ask a universal ecological question that is related to the functioning of bees in general, not only to the functioning of a model organism. The results obtained in this study are informative for detecting the general mechanisms underlying the dependence of bees on their floral resources, including various polylectic and oligolectic bee species, irrespective of their speciesspecific feeding preferences for a definite spectrum of plant species (for obvious reasons, the findings of this study do not apply to monolectic bees feeding on a single plant species).

To study the effects of diets on wild bee performance, $O$. bicornis bee larvae were reared on diets composed of various pollen mixtures. Through the feeding experiment, we were able to independently control and measure (1) the pollen diversity and species composition of larval food, (2) nutritional quality of this food and (3) sexual dimorphism in the effects of diets on bees. Importantly, for every nutritionally deficient diet used in the feeding experiment, a diet composed of the same pollen mixture but artificially supplemented with scarce nutrient(s) was subsequently fed. This approach allowed us to directly study whether inadequate concentrations of specific nutrients were responsible for the observed negative effects of pollen species composition and diversity on bee fitness. Bee fitness was represented by the following life history traits, each of which independently influenced bee fitness: (1) mortality during larval development, (2) adult body mass, (3) cocoon mass, and (4) cocoon development state (cf. Filipiak and Filipiak, 2020). The fully controlled laboratory experiment 
enabled us to conclusively test the influence of a specific factor, the nutritional balance, on organismal traits shaping bee fitness, which would be practically impossible using field study.

\section{Material and methods}

\subsection{Model organism}

We obtained specimens of $O$. bicornis from cane stems $(25-30 \mathrm{~cm}$ in length, $0.6-1 \mathrm{~cm}$ in diameter) mounted in a single case (Kraków, Poland; $50^{\circ} 01^{\prime} 35^{\prime \prime} \mathrm{N}$; $19^{\circ} 54^{\prime} 05^{\prime \prime} \mathrm{E}$; elevation: 213 m.a.s.l., MAAT: $8.7^{\circ} \mathrm{C}$, MAP: $679 \mathrm{~mm}$ ). Adult female bees formed larval cells inside every stem in the trap nest (Fig. S1). Either one female or one male specimen was collected from each stem to be used in the feeding experiment. Female progenies are usually located in the rear part of the stem, while males can be found near the entrance, which facilitated easy sex determination of the specimens to be used in the feeding experiment (Fig. S1; Filipiak, 2018). To collect females, the stems were checked daily for the presence of larval brood cells, and 500 stems containing at least 1-3 larval cells with female eggs were first collected to obtain female specimens. These stems were not used to obtain males. To obtain males, new empty cane stems (ca. 500 stems) were mounted to allow the adult bees to continue laying eggs, and the stems were again checked on a daily basis. Then, every completed stem, i.e., those filled with eggs and closed with mud, was collected to obtain male specimens. In each instance, before mounting stems in the case, we placed ca. 900 cocoons in the vicinity to ensure the use of stems by bees and to obtain the required number of female and male larvae for the laboratory experiment. All stems were kept at $21{ }^{\circ} \mathrm{C}$ and $60 \%$ relative humidity under a 12:12 light:dark photoperiod to allow the eggs to hatch. Three-day-old larvae were used in the experiment due to the fragility and sensitivity of eggs and the possibility of mechanical damage to the eggs during transfer to experimental containers (cf. Filipiak and Filipiak, 2020). This is a standard procedure used in previous studies (e.g., Mokkapati et al., 2021).

\subsection{Pollen collection and analyses}

To prepare the diets for the different experimental treatments, we used pollen pools collected by $O$. bicornis in nature (designated Control-Osmia pollen) and five packs of honeybee polyfloral pollen pellets purchased from different manufacturers (Fig. 1 - stage 1). We divided the polyfloral pollen from each pack according to colour under the naked eye to obtain different pollen pellet pools. This method was validated previously (Filipiak et al., 2017). Each pollen pool was ground manually to obtain a homogenous powder and freeze-dried (Christ Beta 1-8 LDplus vacuum freeze-dryer) to obtain the dry mass needed for the experimental treatments. Freeze-drying was used to obtain dry mass because it did not change the pollen nutritional properties (Morgan et al., 2006; Roos et al., 2017). Subsamples from these homogenized pollen pools were used to perform all analyses and to prepare all experimental treatments. All obtained pollen pools as well as Control-Osmia pollen were analyzed first chemically and then botanically. In the chemical analysis, the concentrations and proportions of $\mathrm{K}, \mathrm{Na}, \mathrm{P}, \mathrm{Cu}$ and $\mathrm{Zn}$ were measured and compared to select pollen pools that could be used in the feeding experiments (Fig. 1 - stage 2). In the botanical analysis, the species composition and diversity of each pollen pool were investigated (Fig. 1 - stage 2). Based on the results obtained from all analyses (see the Results section for details), we chose pollen pools for use to establish the experimental diets (treatments).

\subsection{Pollen pool selection and treatments used in the feeding experiment}

Our previous studies suggested that mismatches between the nutritional supply of pollen and the nutritional demands for building $O$. bicornis bodies and cocoons particularly concern sodium (Na), potassium (K), phosphorous (P), copper (Cu), and zinc (Zn) (Filipiak, 2019; Filipiak et al., 2021; Filipiak and Filipiak, 2020). Therefore, we used the concentrations and proportions of $\mathrm{K}, \mathrm{Na}, \mathrm{P}, \mathrm{Cu}$ and $\mathrm{Zn}$ in the feeding experiment. Balanced nutritional quality was defined as the proportions of $\mathrm{K}, \mathrm{Na}, \mathrm{P}, \mathrm{Cu}$ and $\mathrm{Zn}$ found in pollen collected by $O$. bicornis in nature, and the diet composed of pollen collected from $O$. bicornis nests was used as a control diet (Control-Osmia) in the feeding experiment. Unbalanced nutritional quality of the pollen pool was defined as the scarcity (decreased concentration) of one or more elements in relation to the level(s) of the element(s) in the Control-Osmia pollen diet (Fig. 1 - stage 3). Moreover, two packs of unsorted honeybee-collected polyfloral pollen pellets (hereafter designated Apis1 and Apis2) were found to be similar to Control-Osmia in nutritional quality (i.e., the proportions of $\mathrm{Na}, \mathrm{P}, \mathrm{Cu}$ and $\mathrm{Zn}$ ) but differed in pollen species composition and diversity, and Apis1 differed in species composition from Apis2. We used these pollen pellets as additional control diets to control for the potential effects of breeding $O$. bicornis larvae using pollen pellets collected by honeybees that differed in pollen species composition (Fig. 1 - stage 3).

Ultimately, the following seventeen treatments were established in the feeding experiment (Fig. 1 - stage 4): (i) Control-Osmia - natural larval food collected from $O$. bicornis nests; (ii) Apis1 and Apis2 - two honeybee pollen pellet diets that were similar to Control-Osmia in nutritional quality but differed in pollen species composition and diversity; (iii) four honeybee-collected pollen pellet diets that contained significantly lower levels of specific nutrient(s), namely, -CuZn1 (lower in $\mathrm{Cu}$ and $\mathrm{Zn}$ ), -CuZn2 (lower in $\mathrm{Cu}$ and $\mathrm{Zn}$ ), -KP (lower in $\mathrm{K}$ and P), and -NaP (lower in $\mathrm{Na}$ and P); and (iv) supplemented diets, i.e., for each diet described in (iii), two or three diets containing the same pollen but supplemented with salts of scarce elements were formulated (Fig. 1 - stage 4). Treatments (iii) and (iv) formed four groups of pollen pools designated 'CuZn1', 'CuZn2', 'NaP' and 'KP', and within each pool, each scarce diet (e.g., - $\mathrm{CuZn} 1+\mathrm{H}_{2} \mathrm{O}$ ) was accompanied by supplemented diets (e.g., -CuZn1 + Cu, -CuZn1 + Zn, - CuZn + CuZn). To supplement $\mathrm{Cu}$ and/ or $\mathrm{Zn}$ in the bee diets, we used $\mathrm{CuCl}_{2}$ and/or $\mathrm{ZnCl}_{2}$, respectively. $\mathrm{NaCl}_{2}$ or $\mathrm{NaH}_{2} \mathrm{PO}_{4}$ was used to supplement $\mathrm{Na}, \mathrm{KCl}$ or $\mathrm{KH}_{2} \mathrm{PO}_{4}$ was used to supplement $\mathrm{K}$, and $\mathrm{KH}_{2} \mathrm{PO}_{4}$ or $\mathrm{NaH}_{2} \mathrm{PO}_{4}$ was used to supplement $\mathrm{P}$.

The concentration of every salt added to every pollen diet was adjusted to reflect the concentration of the corresponding element in Control-Osmia using the equation $X_{\text {added }}=X_{\text {Control-Osmia }}-X_{\text {considered pollen diet }}$ where $X$ is the mass of the considered scarce nutrient (i.e., $\mathrm{Cu}, \mathrm{Zn}, \mathrm{K}, \mathrm{Na}$ or $\mathrm{P}$ ) in the whole mass of the pollen diet eaten by a single larva. Note that supplementation of $\mathrm{P}$ with $\mathrm{NaH}_{2} \mathrm{PO}_{4}$ was insufficient to reflect the $\mathrm{P}$ concentration in ControlOsmia pollen (sufficient P supplementation would result in an extremely high Na concentration). A comparison of the measured concentrations of every element in every diet/treatment is provided in the supplement (Table S1).

\subsection{Experimental design}

Twenty-five replicates (Eppendorf tubes, $2 \mathrm{ml}$ ) were prepared per treatment and sex and filled with the corresponding pollen diets. The amounts of pollen added corresponded to the dry mass $(\mathrm{dm})$ of pollen provisions found in O. bicornis nests, i.e., $195 \pm 5 \mathrm{mg} \mathrm{dm}$ for females and $140 \pm 5 \mathrm{mg} \mathrm{dm}$ for males. The dry pollen loads were complemented with either demineralized water (for the experimental control and the pollen mixtures that were low in specific nutrients) or salt solutions (for the supplemented pollen mixtures). The test solutions were added in an amount that was ca. $25 \%$ of the dry pollen mass $-50 \mu \mathrm{l}$ was added to each female provision, and $35 \mu \mathrm{l}$ was added to each male provision using a microliter pipette. Considering the equation above, we added the following masses [g] of each salt to 11 of demineralized water: -CuZn1 - females - $0.021 \mathrm{CuCl}_{2}$ and $0.199 \mathrm{CuZn}_{2}$, males - $0.022 \mathrm{CuCl}_{2}$ and $0.204 \mathrm{CuZn}_{2}$; -CuZn2 - females - $0.027 \mathrm{CuCl}_{2}$ and $0.222 \mathrm{CuZn}_{2}$, males - $0.028 \mathrm{CuCl}_{2}$ and $0.228 \mathrm{CuZn}_{2} ;-\mathrm{KP}-$ females - $12.089 \mathrm{KCl}$ and $22.067 \mathrm{KH}_{2} \mathrm{PO}_{4}$, males $-12.270 \mathrm{KCl}$ and 22.397 $\mathrm{KH}_{2} \mathrm{PO}_{4}$; and -NaP - females - $0.324 \mathrm{NaCl}$ and $0.667 \mathrm{NaH}_{2} \mathrm{PO}_{4}$, males $0.334 \mathrm{NaCl}$ and $0.683 \mathrm{NaH}_{2} \mathrm{PO}_{4}$. Before starting the experiment, the Eppendorf tubes were allowed to stand for $24 \mathrm{~h}$ to allow the water and solutions to penetrate the pollen loads. Three-day-old larvae were assigned to the treatments, with one individual per Eppendorf tube. All experimental 


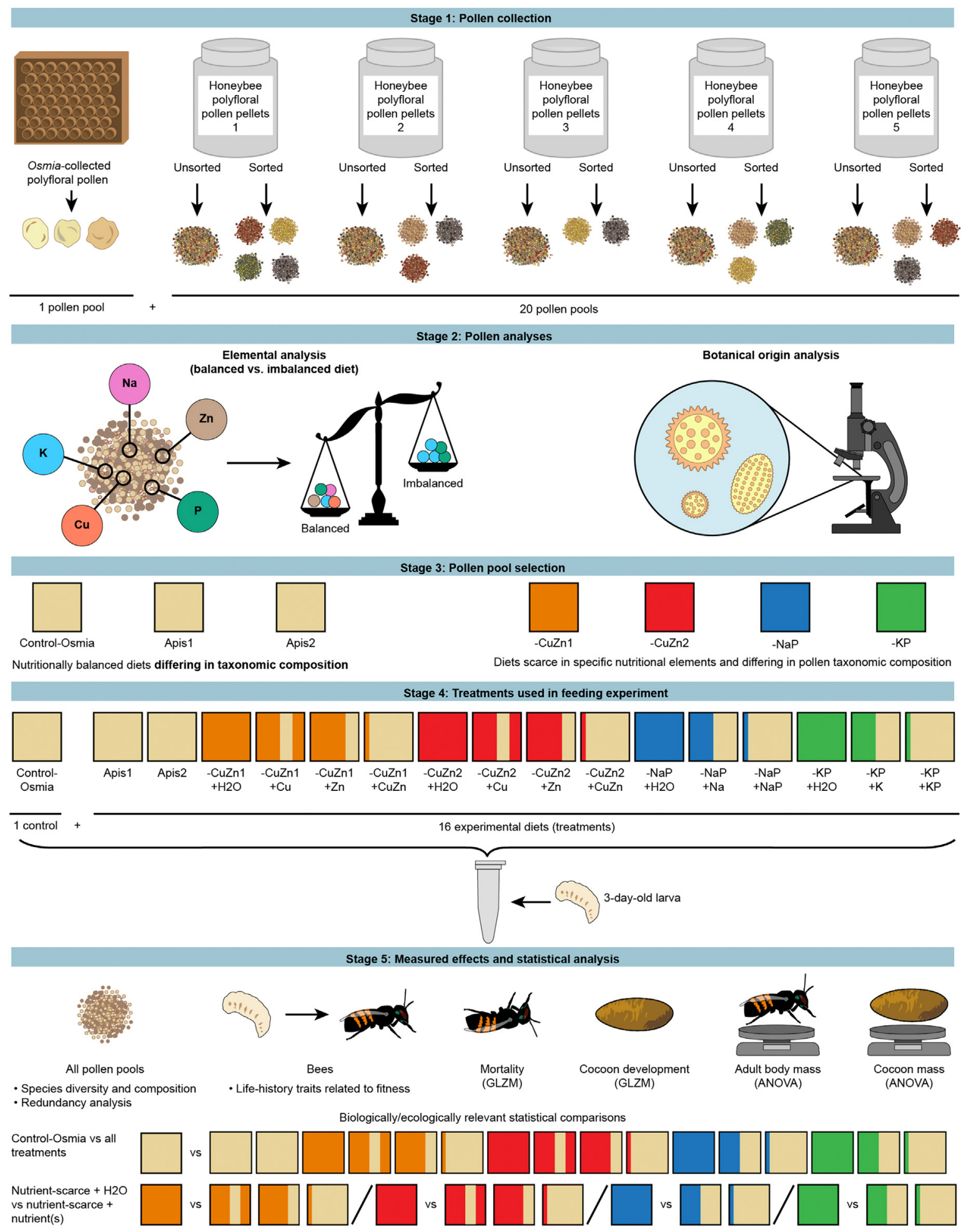

Fig. 1. Experimental setup and measured effects.

tubes were kept open at $21{ }^{\circ} \mathrm{C}$ and $60 \% \mathrm{RH}$ under a 12:12 (L:D)-h photoperiod for 3 months. The exposure period was long enough to ensure that all larvae had gone through the life cycle to reach adulthood, i.e., the stage at which fully developed individuals hibernated in their cocoons (Danforth et al., 2019; Giejdasz and Wilkaniec, 2002; Splitt et al., 2021a). At the end of exposure, the specimens were collected to determine life history traits. The individuals (i.e., the adults and their cocoons) were frozen $\left(-20{ }^{\circ} \mathrm{C}\right)$ and dried using a vacuum drier (at $80{ }^{\circ} \mathrm{C}$ for $48 \mathrm{~h}$ ) to obtain dry mass.

\subsection{Fitness-related life history traits}

We studied the following life-history traits: mortality, cocoon development, body mass and cocoon mass (Fig. 1 - stage 5). The selected parameters are important in population dynamics since (1) mortality is the most relevant trait to study because if a specimen dies before maturation, its fitness is nonexistent; (2) cocoons are secretions made for a specific purpose to enhance bee fitness (providing protection during prewintering and 
overwintering, i.e., during the first ten months of the adult part of the life cycle) (Bosch et al., 2008; Giejdasz and Wilkaniec, 2002); and (3) the mass of adults is correlated with the fitness of $O$. bicornis solitary bee females (this effect is not observed in males (Kim, 1997; Seidelmann, 2014)).

The degree of cocoon development was assessed by qualitative analysis. Four stages of cocoon development were distinguished: (1) a fully developed cocoon that covered the whole bee body and consisted of a hard material; these cocoons were impossible to tear with bare hands but could be cut with a knife because they were sufficiently hard; (2) an almost-developed cocoon that covered the whole bee body but consisted of a soft material; these cocoons were impossible to cut with a knife because they were too soft, but they could be torn by hand; (3) an underdeveloped cocoon that covered only part of the bee body and was soft; and (4) a very underdeveloped cocoon that did not cover any part of the bee body and consisted only of 'woolly' matter. See Fig. S2 for details.

\subsection{Chemical and botanical analyses}

$\mathrm{Zn}, \mathrm{Cu}, \mathrm{Na}$, and $\mathrm{K}$ concentrations were determined by using atomic absorption spectrometry (Perkin-Elmer AAnalyst 200 and Perkin-Elmer AAnalyst 800 ), and the $\mathrm{P}$ content was determined by using colorimetry (MLE FIA). Homogenized and dried samples were used to prepare liquid solutions (digested on a hotplate in a 4:1 mixture of nitric acid (70\%) and hydrogen peroxide (30\%)) for use in the analyses. To determine the analytical precision, certified reference materials (bush, NCS DC 73349; chicken, NCS ZC 73016; and bovine muscle powder, RM8415) were tested along with the samples. In the botanical analysis, the exact species composition (the percentages of every noted taxon) of each distinct pollen pool was estimated by counting the pollen grains under a microscope using two samples of $3.5 \mathrm{~g} \mathrm{dm}$ each from every pollen pool. The plant species were identified according to keys for pollen grain classification and a reference collection. This method was validated previously (Filipiak et al., 2017).

\subsection{Statistical analyses}

We used a series of statistical analyses (1) to explore the effects of pollen diets with various species compositions and diversities on bee fitnessrelated traits and (2) to explore whether observed negative effects were caused by a lack of nutritional balance in the diets.

In the first step, to investigate the species diversity of the pollen diets, we calculated Fisher's alpha as the index of diversity and dominance, D, (i.e., 1 minus the Simpson index, ranging from 0 (all taxa are equally present) to 1 (one taxon dominates the community completely)) (Fisher et al., 1943; Harper, 1999; Magurran, 2013) as the index of dominance using PAST 4.05 (Hammer, 2021; Hammer et al., 2001). Fisher's alpha was used because it is suitable for data sets characterized by high numbers of rare species, which was the case in the present study (see Table S3).

In the second step, we correlated pollen diet species with nutritional composition using redundancy analysis (RDA). This analysis allowed us to explore whether both the nutritional and species compositions differed significantly between diets and whether interaction occurred between the two compositions. RDA was performed only on the pollen species that contributed the most to each pollen pool (i.e., the concentration of pollen grains in a specific pollen pool was higher than 20\%) (CANOCO 5 Smilauer and Lepš, 2014).

In the next step, we focused on the effects of the experimental treatment diets on bees. The effects of the diets on the studied fitness-related traits were separately determined for each parameter (mortality, cocoon development, adult body mass, and cocoon mass). To test the effects of diet, sex and their interaction on mortality and cocoon development, we constructed a generalized linear model (GLZM) in R ( $\mathrm{R}$ Core Team, 2021) using the 'stats' package (R Core Team, 2021) for model fitting and the 'car' package (Fox and Weisberg, 2019) to calculate the $p$-values of factors (Wald Chisquare test, $\mathrm{F}$ test). For mortality, the model also used the 'brglm2' package (Kosmidis, 2021). The error distribution and canonical link function were adapted to response variables as follows: mortality (binomial; logit) and cocoon development (quasi-Poisson; log) (Fox et al., 2015).

Using the data on the masses of adult bees and their cocoons, we performed one-way ANOVA followed by Dunnett's test $(p<0.05$; Statistica 13). Considering that the difference in mass between females and males stems from their biology, i.e., females weighed more than males (Filipiak, 2018), we studied the effects of each treatment on body mass and cocoon mass separately in each sex. Because of the high mortality rates of females in the supplemented -KP treatments $(-\mathrm{KP}+\mathrm{K}$ and $-\mathrm{KP}+\mathrm{KP}$ ) and the $-\mathrm{NaP}+\mathrm{H}_{2} \mathrm{O}$ treatment, the effect of diet on body and cocoon masses in females was impossible to determine (in these cases, the number of individuals equaled 0 to 3 , precluding any reliable statistical analysis).

To investigate the power of the effects caused by nutritional supplementation, we compared every nutrient(s)-scarce treatment with the corresponding nutrient(s)-supplemented treatments for each pollen pool ('CuZn1', 'CuZn2', 'NaP' and 'KP') separately. Similar to the previous analyses, we studied the effects of diet, sex and their interaction on mortality and cocoon development using GLZM, whereas we studied the effects on body mass and cocoon mass in each sex separately using one-way ANOVA with a post hoc Dunnett test. For the -KP and -NaP pollen pools, we studied the effects of the diets on body mass and cocoon mass only in males because of high female mortality (in these cases, the number of individuals equaled 0 to 3 , precluding any reliable statistical analysis). For all models, after both the main factors and their interactions were tested for significance ( $p \leq$ 0.05 ), nonsignificant interactions and/or nonsignificant variables were removed from the model. Whenever a significant interaction was found, the effect on each factor was studied separately.

\section{Results}

\subsection{Pollen pools - nutritional quality, species composition and species diversity}

The pollen pools used in the feeding experiment differed in nutritional quality, as reflected by the proportions of the studied elements (Fig. 2). The Control-Osmia, Apis1 and Apis2 pollens had similar nutritional quality; -CuZn1 and -CuZn2 were scarce in $\mathrm{Cu}$ and $\mathrm{Zn},-\mathrm{KP}$ was scarce in $\mathrm{K}$ and $\mathrm{P}$, and -NaP was scarce in Na and P (Fig. 2). The exact concentrations of the studied elements and their recoveries from the reference materials are shown in Tables S1 and S2, respectively. There was a correlation between the elemental compositions of the pollen pools and the presence of pollen from specific plant species (Fig. 2)—scarcity of $\mathrm{Cu}$ and $\mathrm{Zn}$ was associated with a predominance of Brassica napus pollen, scarcity of $\mathrm{K}$ and $\mathrm{P}$ was associated with a predominance of Anthriscus sp. pollen, and scarcity of Na and $\mathrm{P}$ was associated with a predominance of Aesculus sp. pollen.

The pollen pools differed in both species composition (Table S3) and species diversity, with -CuZn1 as the least diverse and -KP as the most diverse (Tables 1 and 2). The most diverse pollen pool (-KP) also had the lowest dominance value, whereas the -CuZn1 and -CuZn2 pollen pools composed of approx. $80-90 \%$ B. napus pollen grains were the most strongly dominated by a single species (Tables 1 and 2). All nutritionally balanced pollen pools, i.e., Control-Osmia, Apis1, and Apis2, had average species diversity among all studied pools according to the Fisher's alpha and D indices (Table 1) but differed in species composition (Table 2).

\subsection{Mortality}

Mortality was affected by the treatment $\left(\chi^{2}=228.6, p<0.00001\right)$ and the interaction of the treatment and $\operatorname{sex}\left(\chi^{2}=29.9, p=0.03\right)$, indicating that males and females responded differently to the studied diets (Table S4). To determine the pattern of this response, we studied the effects of the treatments on each sex separately. We found a significant effect of the treatment on both females $\left(\chi^{2}=229.3, p<0.00001\right)$ and males $\left(\chi^{2}=\right.$ 159.4, $\mathrm{p}<0.00001$ ). We observed sexual dimorphism in response to $\mathrm{Cu}$ and $\mathrm{Zn}$ scarcity, which negatively affected males but not females 

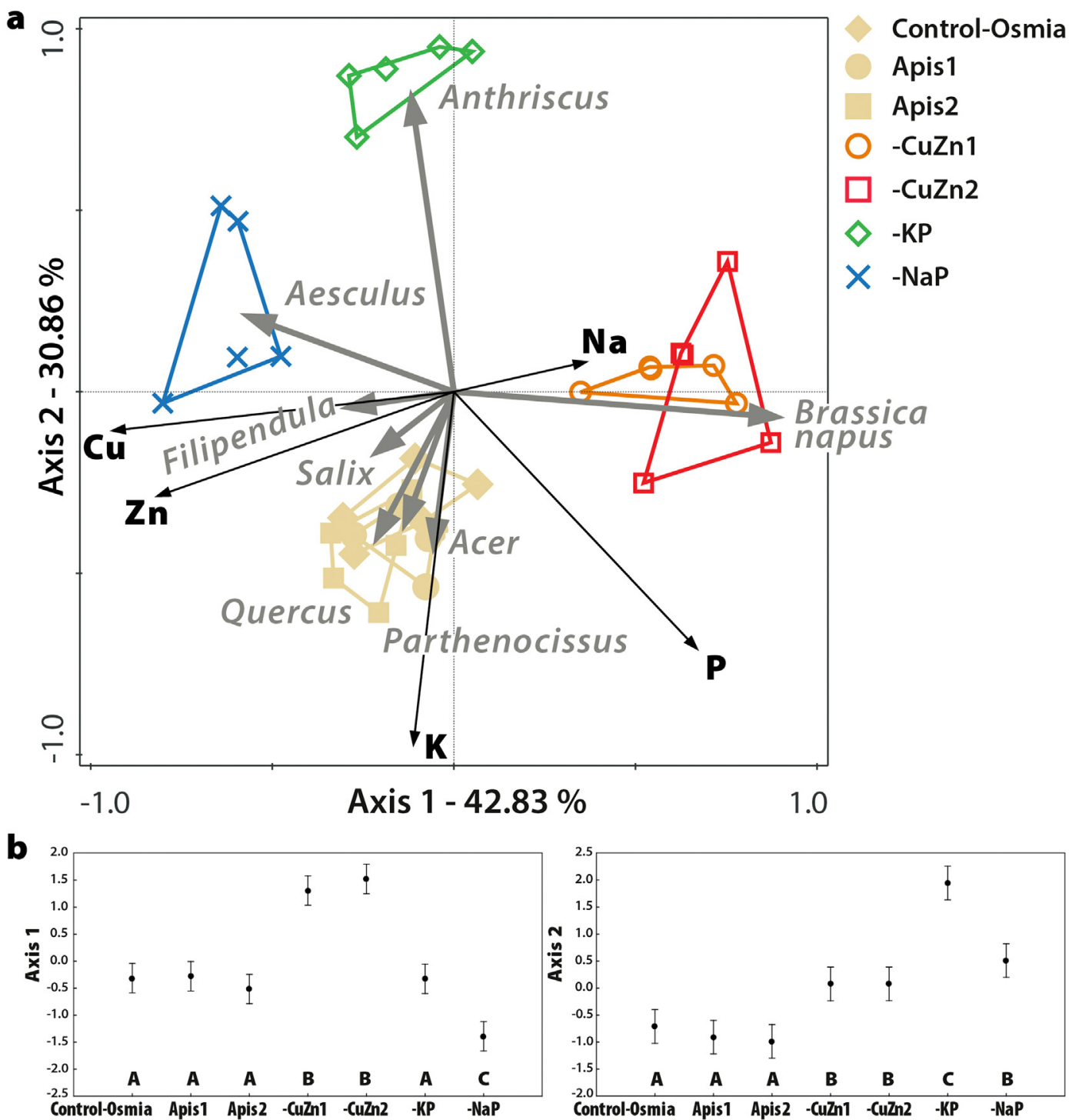

Fig. 2. Multivariate analysis (RDA) of the relationships between the concentrations of the studied elements (P, Na, K, $\mathrm{Zn}$ and $\mathrm{Cu})$ and the proportions of pollen from the dominant taxa (Aesculus, Anthriscus, B. napus, Filipendula, Parthenocissus, Quercus, and Salix) in the pollen pools used in the feeding experiment (Control-Osmia, Apis1, Apis2, -CuZn1, -CuZn2, -KP, and -NaP). (a) RDA plot showing the first two axes and the corresponding percentages of variance explained by these axes (73.69\% in total, $p=0.002$ ); (b) ANOVA performed for the scores for both axes. Different letters denote significant differences between pollen pools, the black dots represent mean values, and the bars denote the confidence intervals (Axis 1: $\mathrm{F}=61.37, p=8 \times 10^{-15}$; Axis $2: \mathrm{F}=45.75, p=3 \times 10^{-13}$ ). The pollen pools differed in elemental composition, which was correlated with the proportions of specific plant taxa composing the pollen pools. The exact concentrations of the studied elements are given in Table S1, and the species composition of each pollen pool is shown in Table S3.

(Table S5). In males, we observed significantly higher mortality in the - $\mathrm{CuZn} 1+\mathrm{H}_{2} \mathrm{O}$ and - $\mathrm{CuZn} 2+\mathrm{H}_{2} \mathrm{O}$ nutritionally poor treatments in comparison with Control-Osmia (Fig. 3 and Table S5), but this effect was not observed in females. Following supplementation with either $\mathrm{Cu}$ or $\mathrm{Zn}$ or both elements, no differences between Control-Osmia and all supplemented treatments $(-\mathrm{CuZn} 1+\mathrm{Cu}, \quad-\mathrm{CuZn} 1+\mathrm{Zn}, \quad-\mathrm{CuZn} 1+\mathrm{CuZn}$,
$-\mathrm{CuZn} 2+\mathrm{Cu},-\mathrm{CuZn} 2+\mathrm{Zn},-\mathrm{CuZn} 2+\mathrm{CuZn})$ were observed in males, indicating that supplementation with $\mathrm{Cu}$ and $\mathrm{Zn}$ completely removed the negative effect on male survivability posed by the scarcity of these nutrients (Fig. 3 and Table S5).

In both males and females, we observed significantly higher mortality rates when bees were reared in the $-\mathrm{KP}+\mathrm{H}_{2} \mathrm{O}$ and $-\mathrm{NaP}+\mathrm{H}_{2} \mathrm{O}$ treatments

Table 1

Diversity indices characterizing the pollen pools used in the feeding experiment based on the number of specimens and taxa of pollen grains composing the pools.

\begin{tabular}{lccccrrr}
\hline & Control-Osmia & Apis1 & Apis2 & -CuZn1 & -CuZn2 & -KP & -NaP \\
\hline Number of taxa & 16 & 21 & 21 & 11 & 27 & 31 & 27 \\
Number of specimens & 946 & 1008 & 1174 & 997 & 1016 & 1471 \\
Dominance (D) & 0.26 & 0.25 & 0.33 & 0.84 & 0.80 & 0.15 \\
Fisher's alpha & 2.74 & 3.75 & 3.63 & 1.73 & 5.09 & 0.44 \\
\hline
\end{tabular}

The dominance (D) value ranges from 0 (all taxa are equally present) to 1 (one taxon dominates the community completely). For Fisher's alpha, a higher value indicates more diversity. See Table S3 for details. 
Table 2

Most numerous pollen species composing the pollen pools used in the feeding experiment.

\begin{tabular}{llrrrrrrr}
\hline & \multicolumn{7}{l}{ Percentage of grains in the pollen pool (\%) } \\
\cline { 2 - 8 } Pollen species & Control-Osmia & Apis1 & Apis2 & -CuZn1 & -CuZn2 & -KP & -NaP \\
\hline Quercus & $\mathbf{4 1 . 0}$ & 8.2 & 0.0 & 0.7 & 1.0 & 0.5 & 0.1 \\
Salix & $\mathbf{2 9 . 0}$ & 0.1 & 0.0 & 0.2 & 0.6 & 3.8 & 3.8 \\
Brassica napus & 0.0 & $\mathbf{3 6 . 3}$ & 0.0 & $\mathbf{9 1 . 5}$ & $\mathbf{8 9 . 3}$ & 0.0 & 0.0 \\
Other Brassicaceae & 1.2 & 0.0 & 1.6 & 0.0 & 0.0 & $\mathbf{2 3 . 2}$ & 3.0 \\
Acer & 4.1 & $\mathbf{2 6 . 5}$ & 0.0 & 2.8 & 1.3 & 0.1 & 0.2 \\
Parthenocissus & 0.0 & 0.0 & $\mathbf{4 4 . 0}$ & 0.0 & 0.1 & 0.1 & 0.1 \\
Filipendula & 0.0 & 0.0 & $\mathbf{3 6 . 5}$ & 0.0 & 0.0 & 16.2 & 1.5 \\
Anthriscus & 0.0 & 0.4 & 0.0 & 1.6 & 0.1 & $\mathbf{2 4 . 8}$ & 0.7 \\
Aesculus & 0.6 & 0.1 & 0.1 & 0.0 & 0.6 & 0.2 & $\mathbf{6 5 . 0}$ \\
\hline
\end{tabular}

For each pollen pool, values for the pollen species composing more than $20 \%$ of the pool are shown in bold. All species found in the pollen pools and their percentages in each pollen pool are presented in Table S3.

as well as their supplemented counterparts $(-\mathrm{KP}+\mathrm{K},-\mathrm{KP}+\mathrm{KP},-\mathrm{NaP}+\mathrm{Na}$, and $-\mathrm{NaP}+\mathrm{NaP}$ ) compared with the Control-Osmia (Fig. 3 and Table S5). Interestingly, the comparison of treatments within the studied pools ('KP' and 'NaP') revealed significant effects of diet, sex and their interaction on mortality (Table S9), showing that females but not males responded to supplementation with K, P and Na (Fig. 3 and Table S10). For the 'KP' pool, we observed a negative effect of supplementation, with higher female mortality in the $-\mathrm{KP}+\mathrm{K}(p=0.001)$ and $-\mathrm{KP}+\mathrm{KP}(p=0.003)$ treatments than in the $-\mathrm{KP}+\mathrm{H}_{2} \mathrm{O}$ treatment. However, for the NaP pool, we observed significantly lower female mortality in the $-\mathrm{NaP}+\mathrm{NaP}$ treatment $(p=0.02)$ than in the $-\mathrm{NaP}+\mathrm{H}_{2} \mathrm{O}$ treatment, which suggested partial mitigation of the negative effect. Therefore, the increased bee mortality observed when fed the -KP and -NaP pollen diets was most likely caused mainly by other (nonstudied) factors in addition to the scarcity of K, P, and Na; nevertheless, female survivability when fed the -NaP diet increased upon supplementing this diet with $\mathrm{Na}$ and $\mathrm{P}$.

\subsection{Cocoon development}

Only the treatment affected cocoon development $\left(\chi^{2}=109.5, p<\right.$ 0.00001 ) (Table S4). We observed reduced cocoon development for all nutritionally scarce treatments (-CuZn1 $+\mathrm{H}_{2} \mathrm{O}$, - $\mathrm{CuZn} 2+\mathrm{H}_{2} \mathrm{O},-\mathrm{KP}+\mathrm{H}_{2} \mathrm{O}$, and $-\mathrm{NaP}+\mathrm{H}_{2} \mathrm{O}$ ) compared with the Control-Osmia (Fig. 4 and Table S6). For both $\mathrm{Cu}$ - and $\mathrm{Zn}$-scarce diets, the negative effect was completely removed only when the diets were supplemented with both $\mathrm{Cu}$ and $\mathrm{Zn}$, indicating that scarcity of $\mathrm{Cu}$ and $\mathrm{Zn}$ may synergistically cause cocoon underdevelopment. Moreover, we observed improved cocoon development after supplementation with either K or KP in comparison with the Control-Osmia (Fig. 4 and Table S6). Similarly, for the 'KP' pollen pool, we observed positive effects of $-\mathrm{KP}+\mathrm{K}(p=0.03)$ and $-\mathrm{KP}+\mathrm{KP}(p=0.0009)$ in comparison with the $-\mathrm{KP}+\mathrm{H}_{2} \mathrm{O}$ treatment (Fig. 4 and Table S12). Importantly, the observed results were mainly due to the improvement in male cocoons and not female cocoons; due to high female mortality, only one female cocoon was found in the $-\mathrm{KP}+\mathrm{K}$ group, and only three were found in the $-\mathrm{KP}+\mathrm{KP}$ group. However, for Na- and P-scarce diets, supplementation of deficient nutrients in -NaP pollen did not reduce the negative effect in comparison with the Control-Osmia (Fig. 4 and Table S6). Therefore, cocoon underdevelopment observed with this diet was not caused by Na and P scarcity.

\subsection{Adult mass}

Both female $(\mathrm{F}=49, p<0.00001)$ and male $(\mathrm{F}=53, \mathrm{p}<0.00001)$ body masses were significantly affected by the treatment (Table S7). Compared with Control-Osmia, in both sexes, reduced body mases were observed in all nutritionally scarce treatments (-CuZn1 $+\mathrm{H}_{2} \mathrm{O}$, - CuZn2 $+\mathrm{H}_{2} \mathrm{O}$, $-\mathrm{KP}+\mathrm{H}_{2} \mathrm{O}$, and $-\mathrm{Na}+\mathrm{H}_{2} \mathrm{O}$, with the latter studied only in males because of high female mortality (Fig. 5 and Table S8)). Following supplementation of the - $\mathrm{CuZn} 1+\mathrm{H}_{2} \mathrm{O}$ and $-\mathrm{CuZn} 2+\mathrm{H}_{2} \mathrm{O}$ diets, we observed a positive response in both sexes (Fig. 5 and Table S8). The effect of reduced male body mass was partially mitigated when the CuZn1 diet was supplemented with $\mathrm{Cu}$

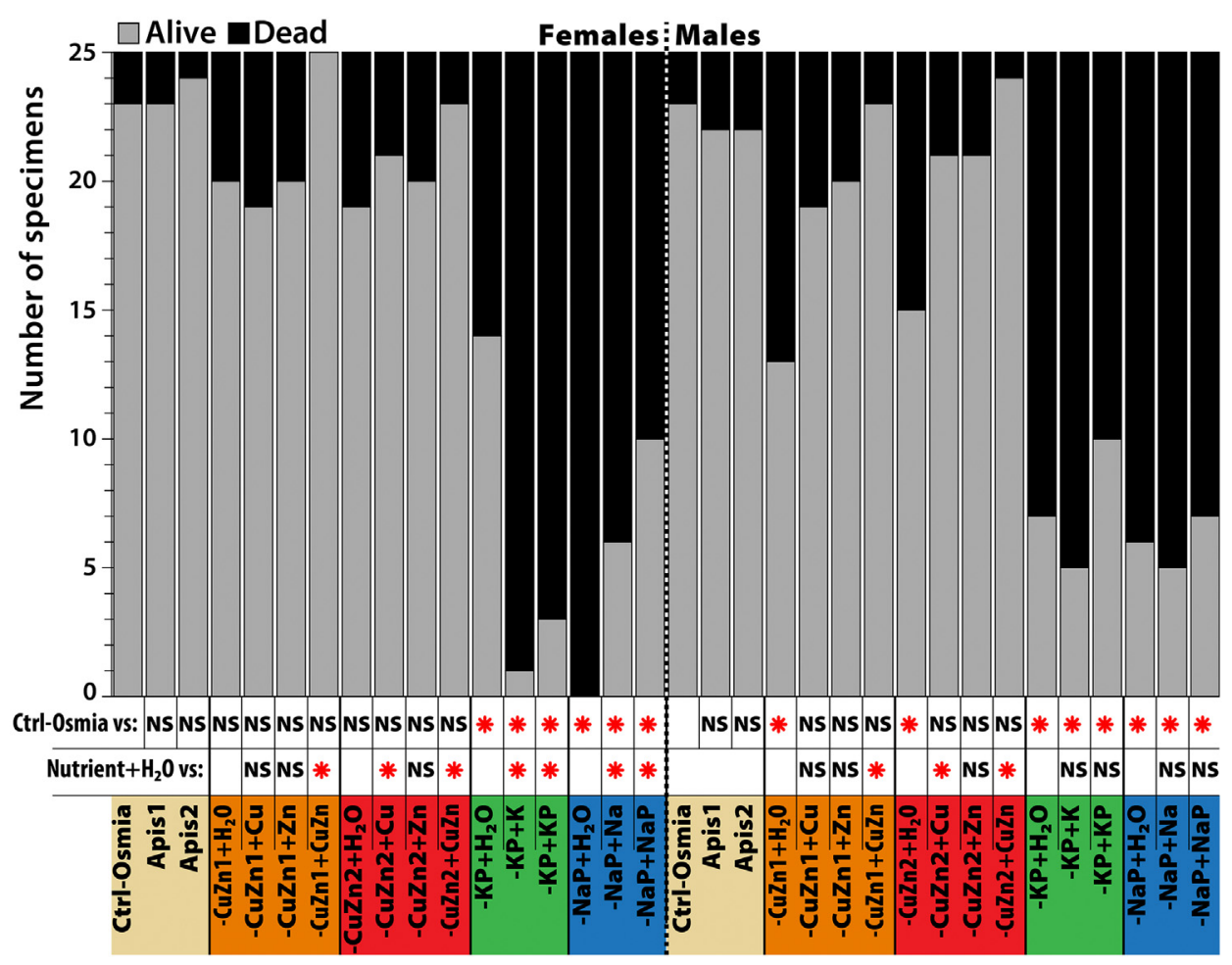

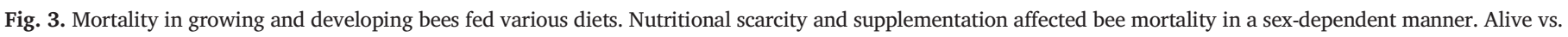

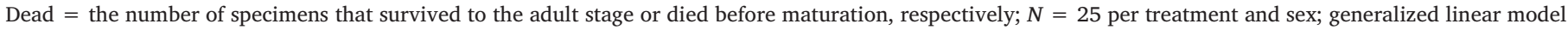

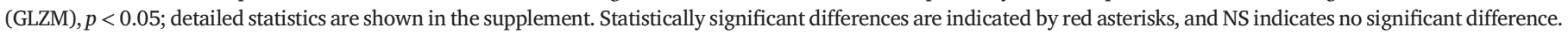




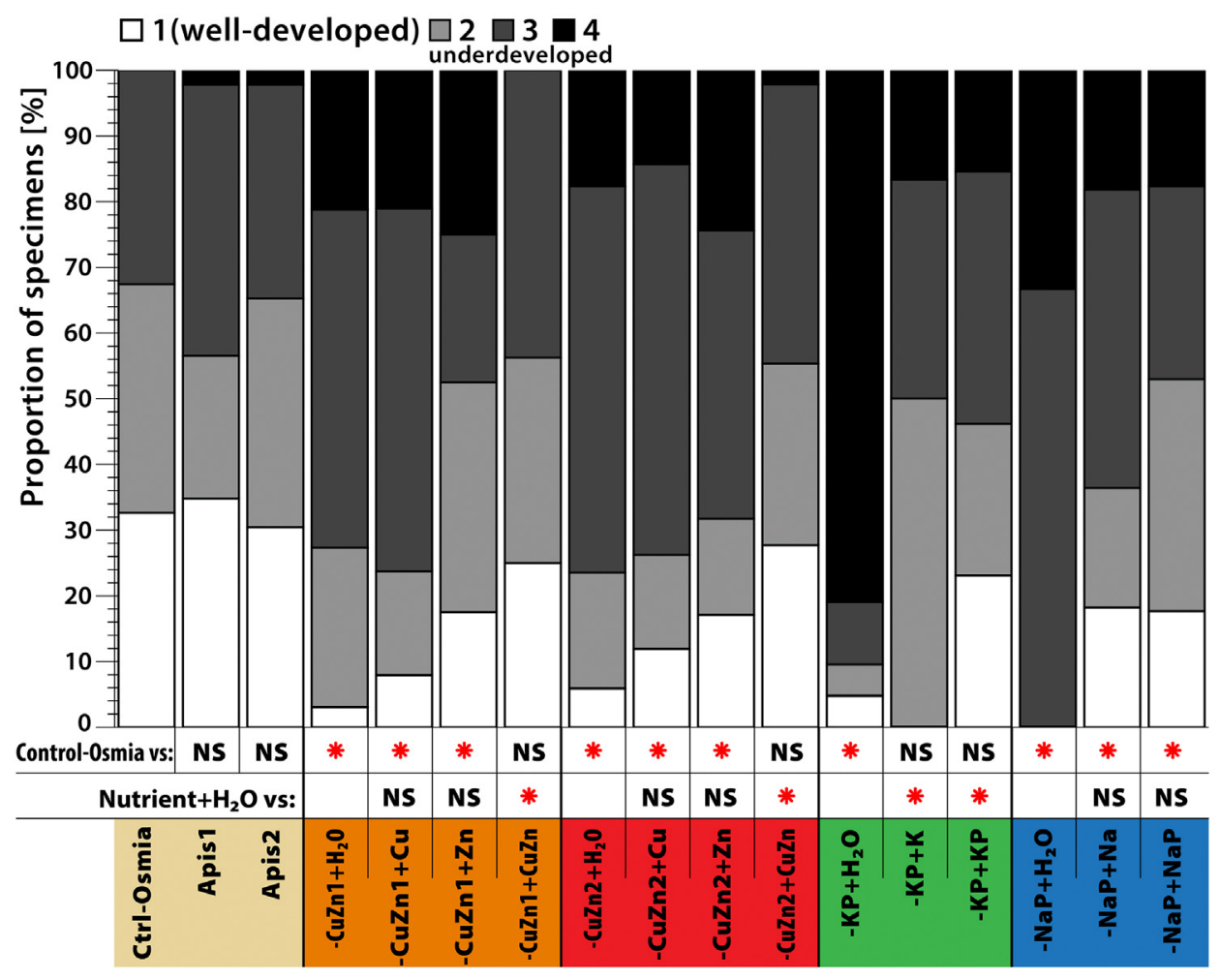

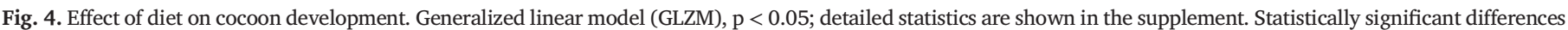
are indicated by red asterisks, minus signs indicate that a statistical comparison was not possible (too few replicates), and NS indicates no significant difference.

and was completely removed when this diet was supplemented with $\mathrm{Zn}$ and $\mathrm{Cu}+\mathrm{Zn}$. In the case of CuZn2, complete removal of the negative effect occurred when the diet was supplemented with $\mathrm{Zn}$, and the addition of $\mathrm{Cu}$ and $\mathrm{Cu}+\mathrm{Zn}$ caused partial mitigation of the negative effect. For females, the negative effect of the -CuZn1 diet on body mass was completely removed upon supplementation with either $\mathrm{Cu}$ or $\mathrm{Zn}$ as well as $\mathrm{Cu}+\mathrm{Zn}$, while the negative effect of the CuZn2 diet was only completely removed upon supplementing the diet with $\mathrm{Cu}+\mathrm{Zn}$. The effects of supplementation with $\mathrm{K}$ and $\mathrm{KP}$ on body mass were not studied in females, and males did not show positive effects in comparison with Control-Osmia (Fig. 5 and Table S8). Additionally, there was no effect of the diet on male body mass for the 'KP' and 'NaP' pollen pools (Fig. 5 and Table S13). Similarly, supplementation of the $-\mathrm{NaP}+\mathrm{H}_{2} \mathrm{O}$ diet with $\mathrm{Na}$ and $\mathrm{NaP}$ did not improve body mass. Overall, the negative effects of the -NaP and -KP diets on body mass were not caused by the scarcity of $\mathrm{K}, \mathrm{Na}$ and $\mathrm{P}$ in these diets.

\subsection{Cocoon mass}

Cocoon mass was affected by diet in both females ( $\mathrm{F}=40, p<0.00001)$ and males ( $\mathrm{F}=19, \mathrm{p}<0.00001)$ (Table S7). Compared with ControlOsmia, females had reduced cocoon masses in all nutritionally scarce treatments, except $-\mathrm{NaP}+\mathrm{H}_{2} \mathrm{O}$, which was not studied. In contrast, males had reduced cocoon masses in almost all nutritionally scarce treatments (-CuZn2 $+\mathrm{H}_{2} \mathrm{O},-\mathrm{KP}+\mathrm{H}_{2} \mathrm{O}$, and $-\mathrm{NaP}+\mathrm{H}_{2} \mathrm{O}$ ), with -CuZn1 $+\mathrm{H}_{2} \mathrm{O}$ having no effect (Fig. 5 and Table S8). The effect of reduced male cocoon mass in $-\mathrm{CuZn} 2+\mathrm{H}_{2} \mathrm{O}$ was completely removed when the diet was supplemented with $\mathrm{Cu}, \mathrm{Zn}$ or $\mathrm{Cu}+\mathrm{Zn}$. In the case of female cocoon mass, the negative effect of the CuZn1 diet was completely removed when the diet was supplemented with either $\mathrm{Cu}$ or $\mathrm{Cu}+\mathrm{Zn}$, and the negative effect of the CuZn2 diet was completely removed upon supplementation with $\mathrm{Cu}+\mathrm{Zn}$. The effect of supplementation of the $-\mathrm{KP}+\mathrm{H}_{2} \mathrm{O}$ diet on female cocoon mass was not studied, and for males, we observed significantly lower cocoon masses in the $-\mathrm{KP}+\mathrm{K}$ and $-\mathrm{KP}+\mathrm{KP}$ treatments than in the Control-Osmia (Fig. 5 and Table S8). Considering the comparisons within pollen pools, in males, the negative effect on cocoon mass was partially mitigated when the -NaP diet was supplemented with $\mathrm{Na}$ and $\mathrm{Na}+\mathrm{P}$ as well as when the -KP diet was supplemented with $\mathrm{K}+\mathrm{P}$ (Fig. 5 and Tables S14 and S15). Thus, the negative effect may be caused by other unstudied factors in addition to the scarcity of $\mathrm{K}, \mathrm{Na}$ and $\mathrm{P}$.

\section{Discussion}

The links between floral diversity, floral species composition and wild bee functioning are unclear, and a better integration of the approaches and frameworks used in various studies is needed (Klaus et al., 2021; Leonhardt et al., 2020; Parreño et al., 2021; Vanderplanck et al., 2020; Wilson et al., 2021; Woodard and Jha, 2017; Zu et al., 2021). In a feeding experiment, we simulated the availability of various pollen species, reflecting food resources available to a model wild bee in different landscapes. We controlled the nutritional quality of the pollen diets using balanced or imbalanced proportions of $\mathrm{Cu}, \mathrm{Zn}, \mathrm{K}, \mathrm{Na}$ and $\mathrm{P}$, showing that the scarcity of these nutrients negatively affected wild bee fitness, whereas their supplementation either fully or partially mitigated the negative effects. Therefore, we suggest that bee fitness may be shaped by the availability of vital nutrients at specific concentrations and ratios associated with specific key plant species. Moreover, we revealed that nutritional balance in the bee larval diet is not connected to the floral diversity of the diet. Based on the obtained results, we provided a conceptual representation of the impact of pollen species availability in the local habitat on the functioning of bee populations (Fig. 6). This conceptual representation is valid for various bee species, irrespective of the specific spectrum of their food plants, since all bees have to nutritionally balance their diets (monolectic bees are an interesting eco-evolutionary exception).

In our study, both the most and least diverse pollen mixtures had limiting effects on bee growth, development and fitness. The limiting effects were most likely associated with the presence of specific plant species responsible for dietary (im)balance. Diminished concentrations of $\mathrm{Cu}$ and Zn were associated with the dominance of Brassica napus (rapeseed); a lack of K and P was associated with a predominance of Anthriscus sp. and Brassicaceae other than rapeseed; and a lack of $\mathrm{Na}$ and $\mathrm{P}$ was associated 


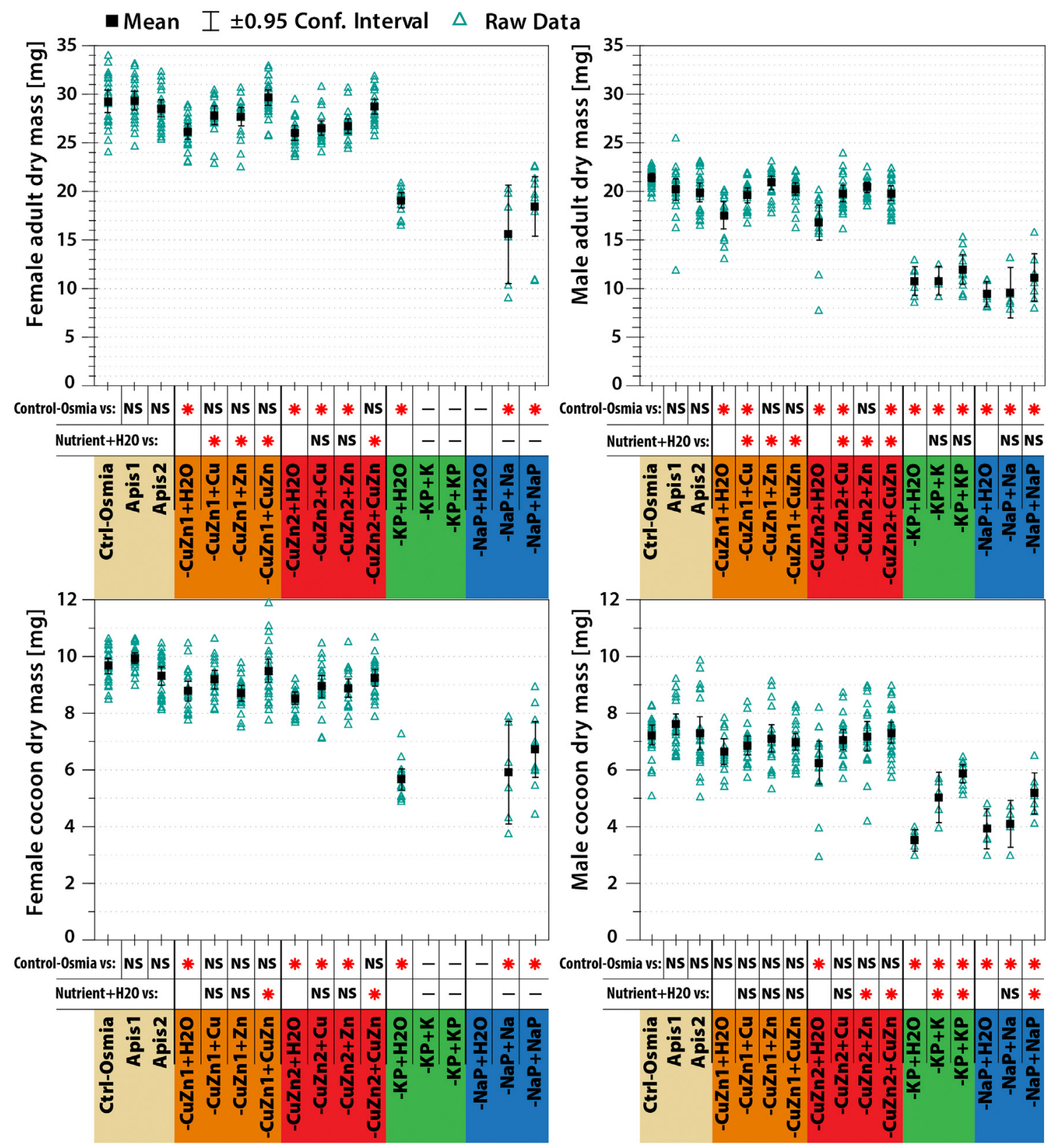

Fig. 5. Effects of diet on adult mass and cocoon mass. ANOVA, $p<0.05$, calculated separately for each sex. Statistically significant differences are indicated by red asterisks, minus signs indicate that a statistical comparison was not possible (too few replicates), and NS indicates no significant difference.

with a predominance of Aesculus sp. Highly concentrated rapeseed pollen in the larval diet increased male bee mortality, inhibited cocoon development in both sexes, decreased body mass in both sexes, and decreased female cocoon mass. Since these negative effects were nonexistent upon supplementing pollen diets lacking $\mathrm{Cu}$ and $\mathrm{Zn}$, we infer that the negative effects were driven by the scarcity of $\mathrm{Cu}$ and $\mathrm{Zn}$. Such negative effects of rapeseed on $O$. bicornis fitness and functioning have also been observed in field studies, e.g., Klaus et al. (2021) observed diminished O. bicornis reproduction in monofloral habitats (100\% rapeseed) compared with that in habitats with more complex floral resources (50\% wildflowers and 50\% rapeseed) in a semifield experiment involving pesticides. Holzschuh et al. (2013) in turn found that almost no $O$. bicornis reproduction occurred in isolated rapeseed fields that were not adjacent to grasslands, whereas reproduction was prominent in rapeseed fields that were adjacent to grasslands as well as in grasslands that were adjacent to rapeseed fields. Interestingly, in the present study, we showed that negative effects posed on bee health and fitness may be removed by supplementing $\mathrm{O}$. bicornis diets with $\mathrm{Zn}$ and $\mathrm{Cu}$ nutrients scarce in rapeseed pollen. This nutritional supplementation may be achieved via the presence of specific plant species whose pollen is rich in these nutrients, e.g., Filipendula sp. This example suggests that to help wild bees in general, simply enriching the floral diversity of their habitats may not be enough, and actions directed toward providing specific plant species to supplement scarce nutrients in bee habitats should be implemented. Importantly, the mixtures of plant species used to improve wild bee diets should be established in relation to local habitats as well as local bee species, as different bee species might need different ratios of nutrients to fulfill their dietary requirements (and, of course, the spectrum of plant species that is used by specific bee species should be considered). Thus, we emphasize that there may be no versatile mixture of plant species seeds that can be distributed throughout the country or continent. Instead, commercially available seed mixtures can be tailored to local needs.

The negative effects imposed on wild bee health and fitness by pollen pools -KP and -NaP were most likely not driven solely by nutritional scarcity in these diets. We observed only partial mitigation of the negative effects on 
pollen allowing Osmia bicornis to achieve an appropriate nutritional balance

pollen impairing larval development of Osmia bicornis via nutritional mismatch between bee demand and plant supply
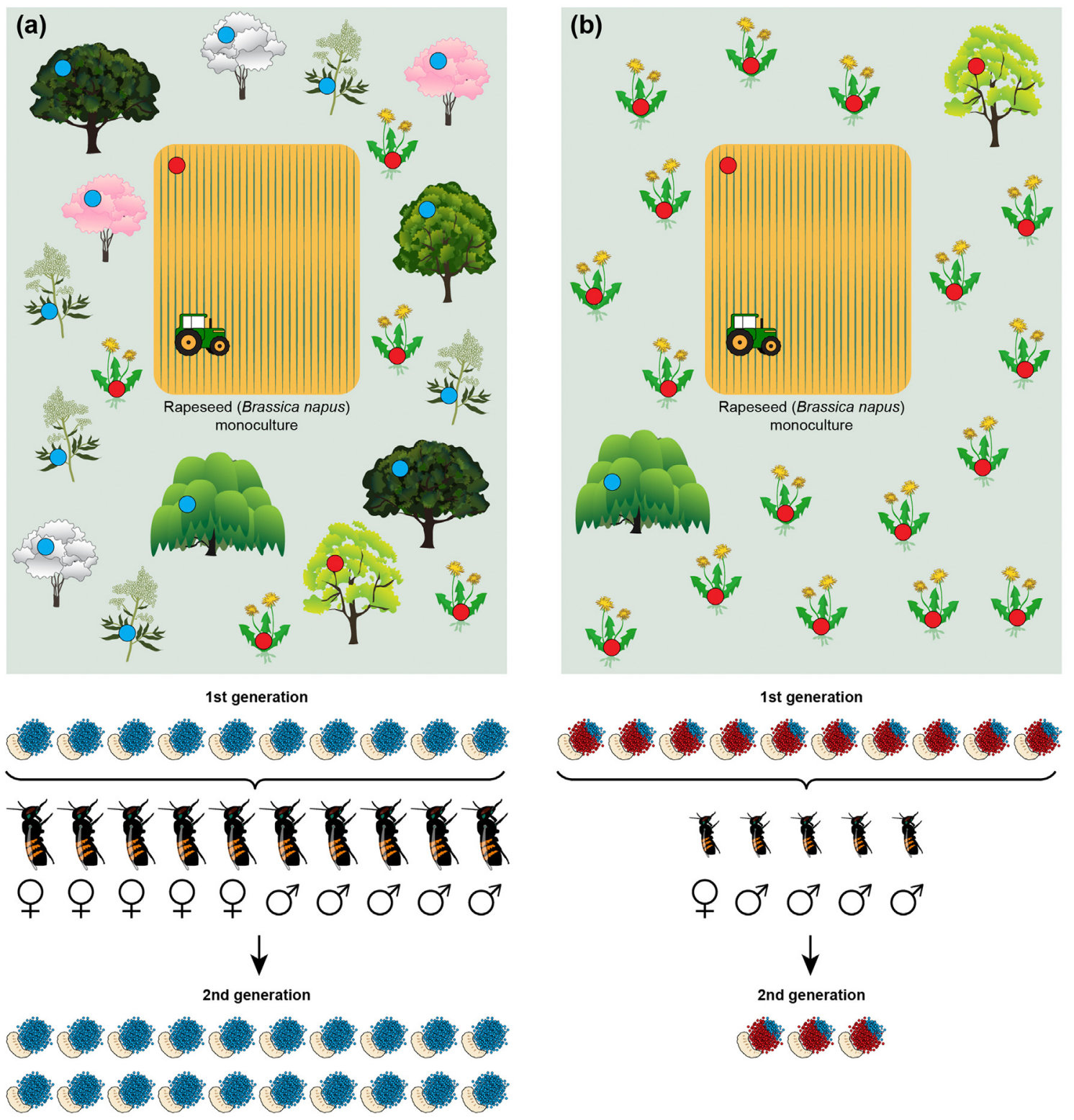

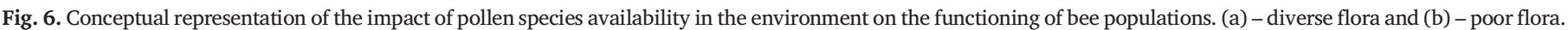

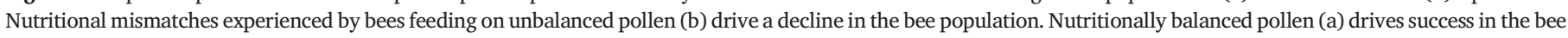

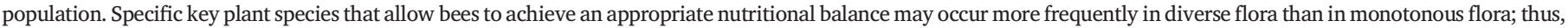

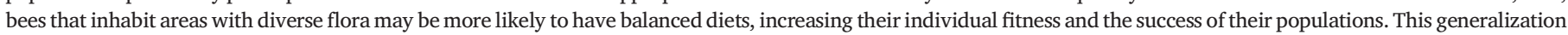

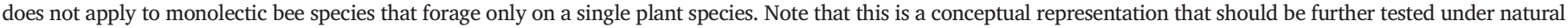
conditions and considering bee species differing in life history, behavior, and nutritional preferences.

female survival and male cocoon mass with nutritional supplementation of the -NaP diet (scarce in Na and P). For the -KP diet (scarce in $\mathrm{K}$ and P), we observed significant improvement of cocoon development as well as a slight increase in male cocoon mass after supplementation with deficient nutrients, indicating that the elements scarce in this diet are important mainly for cocoon formation. The obtained results are in accordance with our previous study showing that the majority of $\mathrm{P}$ acquired during larval development is allocated to the cocoon and that a high proportion of $\mathrm{K}$ intake is used to build cocoons (Filipiak et al., 2021). The lack of improvement after supplementation that occurred in some cases might have been caused by additional (not studied) factors, e.g., the scarcity of colimiting nutrients (other than K, Na and P) (Bryś et al., 2021; Moerman et al., 2017; Vanderplanck et al., 2014; Vaudo et al., 2020; Zu et al., 2021) or the presence of poisonous substances (Eckhardt et al., 2013; Sedivy et al., 2011), various secondary metabolites (Palmer-Young et al., 2019) or the lack of an adequate microbial community (Dharampal et al., 2019, 2020; Steffan et al., 2019). Including at least some of these additional factors and their synergistic effects on bee health and fitness in future laboratory experiments utilizing a fully controlled feeding environment may be highly instructive. We are not aware of any mechanism that could be related to the negative effects on female but not male survival observed after supplementation with $\mathrm{K}$ or $\mathrm{K}$ and $\mathrm{P}$. This issue could be studied in the future.

The pollen diet collected in nature by O. bicornis (Control-Osmia) and the two Apis diets (Apis1 and Apis2), which did not have any negative effects on the bees, had moderate pollen species diversity and dominance. What differentiated these diets from the limiting diets was the specific 
pollen species compositions, which resulted in proportions of the studied nutrients that were balanced for $O$. bicornis. Overall, in all the above three diets, we found large proportions of pollen grains from oaks, willows, and maples as well as Parthenocissus sp. and Filipendula sp., which is in line with literature data (Bednarska et al., 2021; Casanelles-Abella et al., 2021; Splitt et al., 2021b; Teper, 2007), confirming the importance of these species for $O$. bicornis. Therefore, considering the pollen pools directly available to bee larvae, we infer that the species composition of the larval pollen diet is more important for providing an adequate nutritional balance than the diversity of the larval pollen diet.

Below, based on the results from our study, we provide a conceptual representation of the distinction between diverse and poor floral resources and their possible effects on the functioning of wild bee populations. We focused on the availability of key plant species that provide nutritionally balanced diets for $O$. bicornis bees. Let us consider two populations of $O$. bicornis containing the same number of individuals, with a sex ratio of 0.5 females: 0.5 males (this ratio is used for clarity, regardless of the sex ratios that are most common in nature). Both populations are established in seminatural environments consisting of a rapeseed monoculture surrounded by many flowering plants and some trees that produce large amounts of pollen from early to late spring, i.e., during the time window utilized by $O$. bicornis females to collect pollen for their progeny. Population (a) is established among diverse flora offering eight pollen species (Fig. 6a), and population (b) is established among poor flora offering only four pollen species (Fig. 6b). Both floras offer the same amount of pollen. The results from the present study suggest that population (a) might thrive and prosper because the bees are able to collect pollen from their preferred species and thereby compose a nutritionally balanced diet that facilitates proper larval ontogenetic development. Therefore, due to successful overwintering aided by proper cocoon development, in the next generation, the number of individuals will increase. Adult bees are fully developed and of a size that enables them to not only survive but also mate and produce offspring. In the case of population (b), the poor flora offers mainly nutritionally unbalanced pollen. These bees might experience high mortality, have small body sizes and generate underdeveloped cocoons that further increase their mortality. Moreover, the sex ratio in the next generation might be suboptimal because of high mortality in one sex. Overall, population (b) is in decline in this scenario. The mechanism proposed here could result in generalist bees focusing only on a small number of chosen pollen species in diverse environments and collecting a larger number of pollen species (to balance the larval diet) in more uniform environments. Clearly, these are hypothetical scenarios, and our predictions should be further verified under field conditions.

\section{Conclusions}

The occurrence of certain plant species may be important for wild bee populations, as these plants provide nutritionally balanced diets crucial for bee growth and development. Providing a diversity of plant species for bees gives them the opportunity to use their preferred resources, but diversity is not a direct factor driving bee prosperity. Importantly, our study suggests that there is no ideal mix of bee-friendly plants to be used in seed mixes aimed at improving the wild bee food base. Instead, such mixes should be composed considering mismatches between the proportions of nutrients offered by local flora and the nutritional needs of wild bees. Accordingly, to ensure the success of bee conservation efforts, it is not sufficient to use random mixtures of plants known to provide food for specific bee species. Instead, precise mixes of plant species that are used by bees, and also provide nutrients that are scarce in local flora but vital for bee larval development, should be used in bee conservation efforts.

\section{Funding}

Funding for this study was provided by the National Science Centre, Poland (2019/33/B/NZ8/01700) and Jagiellonian University, Faculty of Biology (N18/DBS/000003).

\section{Role of the funding source}

The funding sources had no involvement in the study design; in the collection, analysis and interpretation of data; in the writing of the report; or in the decision to submit the article for publication.

\section{Data availability}

Source data are provided with this paper. All relevant data used in this study are presented in the manuscript and/or in the supplement.

\section{CRediT authorship contribution statement}

Zuzanna M. Filipiak: Conceptualization, Methodology, Validation, Formal analysis, Investigation, Data curation, Writing - original draft, Writing - review \& editing, Visualization. Bożena Denisow: Formal analysis, Resources, Writing - review \& editing. Ernest Stawiarz: Formal analysis, Resources, Writing - review \& editing. Michał Filipiak: Conceptualization, Methodology, Validation, Formal analysis, Investigation, Resources, Data curation, Writing - original draft, Writing - review \& editing, Visualization, Supervision, Project administration, Funding acquisition.

\section{Declaration of competing interest}

The authors declare no competing interests.

\section{Acknowledgements}

We thank Andrzej Antoł for his introductory analyses.

\section{Appendix A. Supplementary data}

Supplementary data to this article can be found online at https://doi. org/10.1016/j.scitotenv.2022.153326.

\section{References}

Ausma, T., Bansal, V., Kraaij, M., Verloop, A.C.M., Gasperl, A., Müller, M., Kopriva, S., De Kok, L.J., van der Kooi, C.J., 2021. Floral displays suffer from sulphur deprivation. Environ. Exp. Bot. 192, 104656. https://doi.org/10.1016/j.envexpbot.2021.104656.

Austin, A., Gilbert, J., 2021. Solitary bee larvae prioritize carbohydrate over protein in parentally provided pollen. Funct. Ecol. 35, 1069-1080. https://doi.org/10.1111/1365-2435. 13746.

Baggett, L.P., Heck, K.L., Frankovich, T.A., Armitage, A.R., Fourqurean, J.W., 2013. Stoichiometry, growth, and fecundity responses to nutrient enrichment by invertebrate grazers in sub-tropical turtle grass (Thalassia testudinum) meadows. Mar. Biol. 160, 169-180. https://doi.org/10.1007/s00227-012-2075-6.

Bednarska, A.J., Mikołajczyk, Ł., Ziółkowska, E., Kocjan, K., Wnęk, A., Mokkapati, J.S., Teper, D., Kaczyński, P., Łozowicka, B., Śliwińska, R., Laskowski, R., 2021. Effects of agricultural landscape structure, insecticide residues, and pollen diversity on the life-history traits of the red mason bee Osmia bicornis. Sci. Total Environ. 809, 151142. https://doi.org/10. 1016/j.scitotenv.2021.151142.

Belsky, J., Joshi, N.K., 2019. Impact of biotic and abiotic stressors on managed and feral bees. Insects 10, 233. https://doi.org/10.3390/insects10080233.

Bosch, J., Sgolastra, F., Kemp, W.P., 2008. Life cycle ecophysiology of Osmia Mason bees used as crop pollinators. In: James, R., Pitts-Singer, T.L. (Eds.), Bee Pollination in Agricultural Eco-systems. Oxford University Press, Oxford, UK, pp. 83-105.

Bryś, M.S., Skowronek, P., Strachecka, A., 2021. Pollen diet-properties and impact on a bee colony. Insects 12, 798. https://doi.org/10.3390/insects12090798.

Casanelles-Abella, J., Müller, S., Keller, A., Aleixo, C., Alós Orti, M., Chiron, F., Deguines, N., Hallikma, T., Laanisto, L., Pinho, P., Samson, R., Tryjanowski, P., Van Mensel, A., Pellissier, L., Moretti, M., 2021. How wild bees find a way in european cities: pollen metabarcoding unravels multiple feeding strategies and their effects on distribution patterns in four wild bee species. J. Appl. Ecol. https://doi.org/10.1111/1365-2664.14063.

Danforth, B.N., Minckley, R.L., Neff, J.L., 2019. The Solitary Bees: Biology, Evolution, Conservation. Princeton University Press, Princeton, NJ.

Dharampal, P.S., Carlson, C., Currie, C.R., Steffan, S.A., 2019. Pollen-borne microbes shape bee fitness. Proc. Biol. Sci. 286, 20182894. https://doi.org/10.1098/rspb.2018. 2894.

Dharampal, P.S., Hetherington, M.C., Steffan, S.A., 2020. Microbes make the meal: oligolectic bees require microbes within their host pollen to thrive. Ecol. Entomol. 45, 1418-1427. https://doi.org/10.1111/een.12926. 
Di Pasquale, G., Alaux, C., Le Conte, Y., Odoux, J.-F., Pioz, M., Vaissière, B.E., Belzunces, L.P., Decourtye, A., 2016. Variations in the availability of pollen resources affect honey bee health. PLoS One 11, e0162818. https://doi.org/10.1371/journal.pone.0162818.

Drossart, M., Gérard, M., 2020. Beyond the decline of wild bees: optimizing conservation measures and bringing together the actors. Insects 11, 649. https://doi.org/10.3390/insects11090649.

Eckhardt, M., Haider, M., Dorn, S., Müller, A., 2013. Pollen mixing in pollen generalist solitary bees: a possible strategy to complement or mitigate unfavourable pollen properties? J. Anim. Ecol. 83, 588-597. https://doi.org/10.1111/1365-2656.12168.

Elser, J.J., Wu, C., González, A.L., Shain, D.H., Smith, H.J., Sommaruga, R., Williamson, C.E., Brahney, J., Hotaling, S., Vanderwall, J., Yu, J., Aizen, V., Aizen, E., Battin, T.J., Camassa, R., Feng, X., Jiang, H., Lu, L., Qu, J.J., Ren, Z., Wen, J., Wen, L., Woods, H.A., Xiong, X., Xu, J., Yu, G., Harper, J.T., Saros, J.E., 2020. Key rules of life and the fading cryosphere: impacts in alpine lakes and streams. Glob. Change Biol. 26, 6644-6656. https://doi.org/ $10.1111 /$ gcb.15362.

Filipiak, M., 2018. A better understanding of bee nutritional ecology is needed to optimize conservation strategies for wild bees-the application of ecological stoichiometry. Insects 9, 85. https://doi.org/10.3390/insects9030085.

Filipiak, M., 2019. Key pollen host plants provide balanced diets for wild bee larvae: a lesson for planting flower strips and hedgerows. J. Appl. Ecol. 56, 1410-1418. https://doi.org/ 10.1111/1365-2664.13383.

Filipiak, Z.M., Filipiak, M., 2020. The scarcity of specific nutrients in wild bee larval food negatively influences certain life history traits. Biology 9, 462. https://doi.org/10.3390/biology9120462.

Filipiak, M., Kuszewska, K., Asselman, M., Denisow, B., Stawiarz, E., Woyciechowski, M., Weiner, J., 2017. Ecological stoichiometry of the honeybee: pollen diversity and adequate species composition are needed to mitigate limitations imposed on the growth and development of bees by pollen quality. PLoS One 12, e0183236. https://doi.org/ 10.1371/journal.pone.0183236.

Filipiak, M., Woyciechowski, M., Czarnoleski, M., 2021. Stoichiometric niche, nutrient partitioning and resource allocation in a solitary bee are sex-specific and phosphorous is allocated mainly to the cocoon. Sci. Rep. 11, 652. https://doi.org/10.1038/s41598020-79647-7.

Fisher, R.A., Corbet, A.S., Williams, C.B., 1943. The relation between the number of species and the number of individuals in a random sample of an animal population. J. Anim. Ecol. 12, 42. https://doi.org/10.2307/1411.

Fox, J., Weisberg, S., 2019. An R companion to applied regression. Sage, Thousand Oaks CA.

Fox, G.A., Negrete-Yankelevich, S., Sosa, V.J., 2015. Ecological statistics: Contemporary theory and application. Oxford University Press, Oxford, UK.

Giejdasz, K., Wilkaniec, Z., 2002. Individual development of the red mason bee (Osmia rufa L., Megachilidae) under natural and laboratory conditions. J. Apic. Sci. 46, 51-57.

Goulson, D., Nicholls, E., Botias, C., Rotheray, E.L., 2015. Bee declines driven by combined stress from parasites, pesticides, and lack of flowers. Science 347, 1255957. https:// doi.org/10.1126/science.1255957.

Hammer, Ø., 2021. Past 4 - the past of the future. https://www.nhm.uio.no/english/ research/infrastructure/past/. (Accessed 10 October 2021).

Hammer, Ø., Harper, D.A.T., Ryan, P.D., 2001. PAST: paleontological statistics software package for education and data analysis. Palaeontol. Electron. 4, 1-9.

Harper, D.A.T., 1999. Numerical palaeobiology: Computer-based modeling and analysis of fossils and their distributions. Wiley-Blackwell, New York, NY.

Hemberger, J., Crossley, M.S., Gratton, C., 2021. Historical decrease in agricultural landscape diversity is associated with shifts in bumble bee species occurrence. Ecol. Lett. 24, 1800-1813. https://doi.org/10.1111/ele.13786.

Holzschuh, A., Dormann, C.F., Tscharntke, T., Steffan-Dewenter, I., 2013. Mass-flowering crops enhance wild bee abundance. Oecologia 172, 477-484. https://doi.org/10.1007/ s00442-012-2515-5.

Jachuła, J., Denisow, B., Wrzesień, M., 2017. Validation of floral food resources for pollinators in agricultural landscape in SE Poland. J. Sci. Food Agric. 98, 2672-2680. https://doi. org $/ 10.1002 /$ jsfa. 8761.

Kaspari, M., 2021. The invisible hand of the periodic table: how micronutrients shape ecology. Annu. Rev. Ecol. Evol. Syst. 52, 199-219. https://doi.org/10.1146/annurevecolsys-012021-090118.

Kaspari, M., Powers, J.S., 2016. Biogeochemistry and geographical ecology: embracing all twenty-five elements required to build organisms. Am. Nat. 188 (Suppl. 1), S62-S73. https://doi.org/10.1086/687576.

Kierat, J., Szentgyörgyi, H., Czarnoleski, M., Woyciechowski, M., 2017. The thermal environment of the nest affects body and cell size in the solitary red mason bee (Osmia bicornis L.). J. Therm. Biol. 68, 39-44. https://doi.org/10.1016/j.jtherbio.2016.11.008.

Kim, J.Y., 1997. Female size and fitness in the leaf-cutter bee Megachile apicalis. Ecol. Entomol. 22, 275-282. https://doi.org/10.1046/j.1365-2311.1997.00062.x.

Klaus, F., Tscharntke, T., Bischoff, G., Grass, I., 2021. Floral resource diversification promotes solitary bee reproduction and may offset insecticide effects - evidence from a semi-field experiment. Ecol. Lett. 24, 668-675. https://doi.org/10.1111/ele.13683.

Kosmidis, I., 2021. brglm2: bias reduction in generalized linear models. $\mathrm{R}$ package version 0.8.1. https://CRAN.R-project.org/package $=$ brglm2. (Accessed 10 October 2021).

Leonhardt, S.D., Lihoreau, M., Spaethe, J., 2020. Mechanisms of nutritional resource exploitation by insects. Insects 11, 570. https://doi.org/10.3390/insects11090570.

Lind, P.R., Jeyasingh, P.D., 2018. Interactive effects of dietary phosphorus and iron on daphnia life history. Limnol. Oceanogr. 63, 1181-1190. https://doi.org/10.1002/ lno.10763.

Magurran, A.E., 2013. Measuring Biological Diversity. Wiley-Blackwell, Malden, MA

Moerman, R., Vanderplanck, M., Fournier, D., Jacquemart, A.-L., Michez, D., 2017. Pollen nutrients better explain bumblebee colony development than pollen diversity. Insect Conserv. Divers. 10, 171-179. https://doi.org/10.1111/icad.12213.

Mokkapati, J.S., Bednarska, A.J., Laskowski, R., 2021. The development of the solitary bee Osmia bicornis is affected by some insecticide agrochemicals at environmentally relevant concentrations. Sci. Total Environ. 775, 145588. https://doi.org/10.1016/j.scitotenv. 2021.145588.

Morgan, C.A., Herman, N., White, P.A., Vesey, G., 2006. Preservation of micro-organisms by drying; a review. J. Microbiol. Methods 66, 183-193. https://doi.org/10.1016/j.mimet. 2006.02.017.

Palmer-Young, E.C., Farrell, I.W., Adler, L.S., Milano, N.J., Egan, P.A., Junker, R.R., Irwin, R.E., Stevenson, P.C., 2019. Chemistry of floral rewards: intra- and interspecific variability of nectar and pollen secondary metabolites across taxa. Ecol. Monogr. 89, e01335. https://doi.org/10.1002/ecm.1335.

Parreño, M.A., Alaux, C., Brunet, J.L., Buydens, L., Filipiak, M., Henry, M., Keller, A., Klein, A.M., Kuhlmann, M., Leroy, C., Meeus, I., Palmer-Young, E., Piot, N., Requier, F., Ruedenauer, F., Smagghe, G., Stevenson, P.C., Leonhardt, S.D., 2021. Critical links between biodiversity and health in wild bee conservation. Trends Ecol. Evol. 1-13. https://doi.org/10.1016/j.tree.2021.11.013.

R Core Team, 2021. R: A language and environment for statistical computing. R Foundation for Statistical Computing, Vienna, Austria.

Roos, Y.H., Furlong, C., Potes, N., 2017. Freezing and freeze-drying. In: Roos, Y.H., Livney, Y.D. (Eds.), Engineering Foods for Bioactives Stability and Delivery. Springer, New York, NY, pp. 247-260.

Roulston, T.A.H., Goodell, K., 2011. The role of resources and risks in regulating wild bee populations. Annu. Rev. Entomol. 56, 293-312. https://doi.org/10.1146/annurev-ento120709-144802.

Sardans, J., Janssens, I.A., Ciais, P., Obersteiner, M., Peñuelas, J., 2021. Recent advances and future research in ecological stoichiometry. Perspect. Plant Ecol. Evol. Syst. 50, 125611. https://doi.org/10.1016/j.ppees.2021.125611.

Sedivy, C., Müller, A., Dorn, S., 2011. Closely related pollen generalist bees differ in their ability to develop on the same pollen diet: evidence for physiological adaptations to digest pollen. Funct. Ecol. 25, 718-725. https://doi.org/10.1111/j.1365-2435. 2010.01828.x.

Seidelmann, K., 2014. Optimal progeny body size in a solitary bee, Osmia bicornis (Apoidea: Megachilidae). Ecol. Entomol. 39, 656-663. https://doi.org/10.1111/ een. 12145.

Smilauer, P., Lepš, J., 2014. Multivariate analysis of ecological data using CANOCO 5. Cambridge University Press, Cambridge, UK.

Splitt, A., Schulz, M., Skórka, P., 2021a. Current state of knowledge on the biology and breeding of the solitary bee - Osmia bicornis. J. Apic. Res. 0, 1-17. https://doi.org/10.1080/ 00218839.2021.1957610.

Splitt, A., Skórka, P., Strachecka, A., Borański, M., Teper, D., 2021b. Keep trees for bees: pollen collection by Osmia bicornis along the urbanization gradient. Urban Urban Green 64, 127250. https://doi.org/10.1016/j.ufug.2021.127250.

Steffan, S.A., Dharampal, P.S., Danforth, B.N., Gaines-Day, H.R., Takizawa, Y., Chikaraishi, Y., 2019. Omnivory in bees: elevated trophic positions among all major bee families. Am. Nat. 194, 414-421. https://doi.org/10.1086/704281.

Stein, D.S., Debinski, D.M., Pleasants, J.M., Toth, A.L., 2020. Evaluating native bee communities and nutrition in managed grasslands. Environ. Entomol. 49, 717-725. https://doi. org/10.1093/ee/nvaa009.

Sterner, R.W., Elser, J.J., 2002. Ecological stoichiometry: The biology of elements from molecules to the biosphere. Princeton University Press, Princeton, NJ.

Szentgyörgyi, H., Moroń, D., Nawrocka, A., Tofilski, A., Woyciechowski, M., 2017. Forewing structure of the solitary bee Osmia bicornis developing on heavy metal pollution gradient. Ecotoxicology 26, 1031-1040. https://doi.org/10.1007/s10646017-1831-2.

Teper, D., 2007. Food plants of the red mason bee (Osmia rufa L.) determined based on a palynological analysis of faeces. J. Apic. Sci. 51, 55-62.

Trinkl, M., Kaluza, B.F., Wallace, H., Heard, T.A., Keller, A., Leonhardt, S.D., 2020. Floral species richness correlates with changes in the nutritional quality of larval diets in a stingless bee. Insects 11, 125. https://doi.org/10.3390/insects11020125.

Van der Kooi, C.J., Vallejo-Marín, M., Leonhardt, S.D., 2021. Mutualisms and (A)symmetry in plant-pollinator interactions. Curr. Biol. 31, R91-R99. https://doi.org/10.1016/j.cub. 2020.11.020.

Vanderplanck, M., Moerman, R., Rasmont, P., Lognay, G., Wathelet, B., Wattiez, R., Michez, D., 2014. How does pollen chemistry impact development and feeding behaviour of polylectic bees? PLoS One 9, e86209. https://doi.org/10.1371/journal. pone.0086209.

Vanderplanck, M., Gilles, H., Nonclercq, D., Duez, P., Gerbaux, P., 2020. Asteraceae paradox: chemical and mechanical protection of taraxacum pollen. Insects 11, 304. https://doi. org/10.3390/insects11050304.

Vaudo, A.D., Tooker, J.F., Grozinger, C.M., Patch, H.M., 2015. Bee nutrition and floral resource restoration. Curr. Opin. Insect Sci. 10, 133-141. https://doi.org/10.1016/j.cois. 2015.05.008.

Vaudo, A.D., Tooker, J.F., Patch, H.M., Biddinger, D.J., Coccia, M., Crone, M.K., Fiely, M., Francis, J.S., Hines, H.M., Hodges, M., Jackson, S.W., Michez, D., Mu, J., Russo, L., Safari, M., Treanore, E.D., Vanderplanck, M., Yip, E., Leonard, A.S., Grozinger, C.M., 2020. Pollen protein: lipid macronutrient ratios may guide broad patterns of bee species floral preferences. Insects 11, 132. https://doi.org/10.3390/insects11020132.

Wilson, R.S., Keller, A., Shapcott, A., Leonhardt, S.D., Sickel, W., Hardwick, J.L., Heard, T.A., Kaluza, B.F., Wallace, H.M., 2021. Many small rather than few large sources identified in long-term bee pollen diets in agroecosystems. Agric. Ecosyst. Environ. 310, 107296. https://doi.org/10.1016/j.agee.2020.107296.

Wood, T.J., Vanderplanck, M., Vastrade, M., Vaudo, A.D., Michez, D., 2021. Trees for bees: could woody plant pollen be used as a consistent resource in bee-focused agrienvironment schemes? Entomol. Gen. https://doi.org/10.1127/entomologia/2021/ 1241.

Woodard, S.H., Jha, S., 2017. Wild bee nutritional ecology: predicting pollinator population dynamics, movement, and services from floral resources. Curr. Opin. Insect Sci. 21, 83-90. https://doi.org/10.1016/j.cois.2017.05.011. 
Wright, G.A., Nicolson, S.W., Shafir, S., 2018. Nutritional physiology and ecology of honey bees. Annu. Rev. Entomol. 63, 327-344. https://doi.org/10.1146/annurev-ento020117-043423.

Zajdel, B., Borański, M., Kucharska, K., Jojczyk, A., Brzezińska, K., 2019. Bumblebee communities (Apidae, Bombini) in urban parks in relation to park area and other characteristics. Pol. J. Ecol. 67, 84-93. https://doi.org/10.3161/15052249PJE2019.67.1.007.

Zhang, P., van den Berg, R.F., van Leeuwen, C.H.A., Blonk, B.A., Bakker, E.S., 2018. Aquatic omnivores shift their trophic position towards increased plant consumption as plant stoichiometry becomes more similar to their body stoichiometry. PLoS One 13, e0204116. https://doi.org/10.1371/journal.pone.0204116.

Zu, P., Koch, H., Schwery, O., Pironon, S., Phillips, C., Ondo, I., Farrell, I.W., Nes, W.D., Moore, E., Wright, G.A., Farman, D.I., Stevenson, P.C., 2021. Pollen sterols are associated with phylogeny and environment but not with pollinator guilds. New Phytol. 230, 1169-1184. https://doi.org/10.1111/nph.17227. 